Martin, L., Dulmen, S. van, Spelten, E., Jonge, A. de, Cock, P. de, Hutton, E. Prenatal counseling for congenital anomaly tests: parental preferences and perceptions of midwife performance.

Prenatal Diagnosis: 2013, 33(4), 341-353

\begin{tabular}{|l|l|}
\hline $\begin{array}{l}\text { Postprint } \\
\text { Version }\end{array}$ & 1.0 \\
\hline Journal website & http://onlinelibrary.wiley.com/doi/10.1002/pd.4074/abstract \\
\hline Pubmed link & $\underline{\text { http://www.ncbi.nlm.nih.gov/pubmed/23447385 }}$ \\
\hline DOI & $10.1002 /$ pd.4074 \\
\hline
\end{tabular}

This is a NIVEL certified Post Print, more info at http://www.nivel.eu

\title{
Prenatal counseling for congenital anomaly tests: parental preferences and perceptions of midwife performance
}

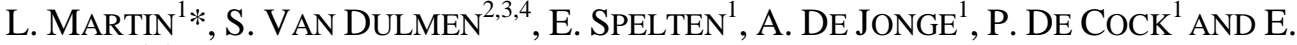 \\ HUTTON $^{1,5}$ \\ ${ }^{1}$ Department of Midwifery Science, AVAG and the EMGO ${ }^{+}$Institute for Health and Care \\ Research, VU University Medical Centre, Amsterdam, The Netherlands \\ ${ }^{2}$ Netherlands Institute for Health Services Research (NIVEL), Utrecht, The Netherlands \\ ${ }^{3}$ Department of Primary and Community Care, Radboud University Nijmegen Medical \\ Centre, Nijmegen, The Netherlands \\ ${ }^{4}$ Department of Health Sciences, Buskerud University College, Drammen, Norway \\ ${ }^{5}$ Obstetrics and Gynecology, Midwifery Education Program, McMaster University, Hamilton, \\ Ontario, Canada *Correspondence to: Linda Martin. E-mail: linda.martin@inholland.nl
}

\begin{abstract}
Objective Evidence-based instruments to evaluate the preferences and experiences of future parents regarding prenatal counseling for congenital anomaly tests are currently lacking. We developed the quality of care through clients' eyes prenatal questionnaire (QUOTEprenatal), a client-centered instrument, and assessed its components.

Furthermore, the QUOTEprenatal was used to provide insight into (1) clients' previsit preferences and (2) clients' postvisit experience, that is, perceived care provider performance regarding the counseling they received.

Method In the questionnaire survey, a principal component analysis was used to gain insight into the underlying components of the questionnaire. Regression analysis was performed to examine differences between groups.

Results In 17 Dutch midwifery practices, 941 pregnant women and their partners (response rate 79\%) completed the 59-item QUOTEprenatal previsit and postvisit, measuring preferences and perceived performances, respectively. A principal component analysis revealed three counseling components: clientmidwife relation, health education and decision-making support. Reponses showed that, previsit, most clients consider the client-midwife relationship and health education to be (very) important. One third of the clients consider decision-making support to be (very) important. Nulliparae had higher preferences for health education and decision-making support than multiparae.
\end{abstract}


Martin, L., Dulmen, S. van, Spelten, E., Jonge, A. de, Cock, P. de, Hutton, E. Prenatal counseling for congenital anomaly tests: parental preferences and perceptions of midwife performance. Prenatal Diagnosis: 2013, 33(4), 341-353

Conclusion Clients perceive that their midwives perform well in building the client-midwife relationship and in giving health education. Improvement is needed in decision-making support.

\section{INTRODUCTION}

Over the last decades, prenatal testing for congenital anomalies has developed substantially. ${ }^{1-3}$ In the Western world, prenatal tests, such as first and second trimester ultrasounds, are increasingly offered as routine prenatal care, although in fact they are not; clients have the right to refuse such tests. ${ }^{4-7}$ Consequently, to help future parents decide whether or not to accept these tests, midwives, gynecologists, and genetic counselors have to offer prenatal counseling including decision-making support. This counseling should be nonbiased (i.e. the counselor does not make the decision or give advice about whether or not to have prenatal tests) and informative, encompassing health educational aspects as well as decision-making support. ${ }^{7-11}$ Many process and outcome studies have been carried out to assess the quality of prenatal counseling from the perspective of what care providers think clients should know to make informed choices. Quality measures typically include risk perception accuracy, recall of information provided, decisionrelated outcomes, psychological adjustment and communication style of the counselor. ${ }^{9,12}$ Considerably less research has focused on the perspective of the clients, such as their preferences regarding counseling for prenatal congenital anomaly tests and the extent to which these preferences aremet. The resulting lack of insight into client preferences is striking, because within health care, optimizing client empowerment, health decisions and health behavior requires tailored communication, that is, communication that focuses on individuals' preferences, interests and concerns. ${ }^{13-19}$ Awareness of client preferences is a prerequisite for tailored communication. Insight into clients' preferences regarding decision-making support, which are of utmost importance given the gravity of the decision parents may be facing, is particularly lacking. ${ }^{20}$ As far as we know, no validated instrument exists to evaluate the preferences and experiences of future parents regarding prenatal counseling.

For the present study, we developed the quality of care through clients' eyes prenatal questionnaire (QUOTE ${ }^{\text {prenatal }}$ ) to assess parental preferences and experiences regarding prenatal counseling for congenital anomaly tests, with a focus on both the counseling process and content. In the literature, there is consensus about the health education and decision making support functions of prenatal counseling. ${ }^{9,21}$ However, it is unclear to what extent clients value these functions as important and to what extent these values differ between clients. We therefore compared preferences and experiences within pregnant women and their partners and nulliparous and multiparous women, and finally, we considered the influence of age. Older women have an increased risk of giving birth to a child with a chromosomal abnormality, and therefore, in the Netherlands, women 36 years and older are offered free prenatal testing. ${ }^{22}$ In summary, there are no instruments available that assess clients' and their partners' preferences and experiences regarding prenatal counseling for congenital anomaly tests.

The first aim of this study was to develop such an instrument on the basis of their input, that is, following the quality of care through clients' eyes (QUOTE) 
Martin, L., Dulmen, S. van, Spelten, E., Jonge, A. de, Cock, P. de, Hutton, E. Prenatal counseling for congenital anomaly tests: parental preferences and perceptions of midwife performance. Prenatal Diagnosis: 2013, 33(4), 341-353

procedure. ${ }^{19}$ Secondly, using this instrument, we explored preferences and nivel experiences within a large group of clients and their partners. More specifically, we assessed (1) clients’ previsit preferences regarding prenatal counseling, (2) clients' experiences [the level of perceived performance regarding issues clients value as (very) important], (3) consistency of previsit preferences between women and partners, nulliparae and multiparae, and women younger than and at or older than 36 years of age, and (4) differences in postvisit experiences between the same groups.

\section{METHODS}

The study was conducted in the Dutch healthcare context in which midwives offer prenatal counseling to almost $80 \%$ of the pregnant women. ${ }^{43}$ Dutch midwives have to pass a training course in genetic knowledge and counseling skills to provide prenatal counseling for congenital anomaly tests to low-risk couples. Couples at increased risk for having a child with a congenital anomaly are referred to clinical geneticists.

\section{PARTICIPANTS}

Seventeen midwifery practices in the Netherlands were purposefully selected so as to include different-sized practices from all over the country. ${ }^{23}$ Participants were recruited from all consecutive new clients (women and their partners), between June 2010 and May 2011. Eligible clients were clients (1) new to counseling about prenatal tests for the current pregnancy, (2) 18 years or older, and (3) able to read Dutch or English.

Partners were included only if the pregnant women agreed to participate. Participants were not paid for participating in this study.

\section{INSTRUMENTS}

The self-administered questionnaire contained items on sociodemographic variables and medical background. These questions were completed before the visit.

Background characteristics of nonresponders were recorded by the practice assistant.

\section{QUOTE $^{\text {prenatal }}$ : measurement of preferences and experience}

We developed an instrument based on QUOTE questionnaires.

These are a group of standardized and validated survey questionnaires aimed at investigating preferences and actual experiences of clients previsit and postvisit, respectively. ${ }^{19,24,25}$ The degree to which (perceived) performances of health and societal care services meet the preferences of persons is defined as quality of care. Attention is paid to quality of generic communication items and target-group-related or specific items. ${ }^{24}$ The QUOTE ${ }^{\text {prenatal }}$ was based on semistructured interviews with couples $(\mathrm{N}=12)$ and future mothers $(\mathrm{N}=5)$, existing QUOTE questionnaires ${ }^{24,26}$ and guidelines for prenatal counseling. ${ }^{13}$ The resulting QUOTE ${ }^{\text {prenatal }}$ consists of 59 items. This includes generic items, such as 'It is important to me that the midwife takes my concerns seriously'; prenatal-specific items, such as 'It is important to me that the midwife explains which abnormality can be identified using prenatal screening'; and three organizational items. The importance part of the questionnaire asks parents to rate the extent to which specific aspects of information and communication are considered important prior to counseling about prenatal tests ('preferences'), measured by a 4-point Likert scale ('It is important to me that the 
Martin, L., Dulmen, S. van, Spelten, E., Jonge, A. de, Cock, P. de, Hutton, E. Prenatal counseling for congenital anomaly tests: parental preferences and perceptions of midwife performance. Prenatal Diagnosis: 2013, 33(4), 341-353

midwife . . ’’ ‘1 = not important’, ‘2 = fairly important’, ‘3 = important’, and ‘ 4 = very important').

In the postvisit questionnaire, parents are asked to report whether they perceive that these aspects were attended to during the actual counseling, measured by a 4-point Likert scale ('During the visit, the midwife. . ': ' $1=$ no', ' $2=$ a little', ' $3=$ yes', and ' 4 = very much'). ${ }^{19,24}$ The QUOTE ${ }^{\text {prenatal }}$ was translated into English by a professional translator and double-checked by a second one. Validation was limited to the Dutch version because of the expected small sample size of English-speaking participants.

\section{DATA ANALYSIS}

\section{Quality of care through clients' eyes prenatal questionnaire}

A principal component analysis (PCA) with varimax rotation was performed on the importance scores. ${ }^{24,27}$ The three organizational items were left out of the PCA; results were analyzed separately. The appropriateness of the factor analytic model for the remaining 56 items was tested using the Kaiser- Meyer-Olkin measure of sampling adequacy and Barlett's test of sphericity. Items failing to load at least $0.32^{28}$ on any component were left out. Cronbach's a was rated to assess the internal consistency of the QUOTE categories. ${ }^{19,29}$ Item total correlations (ITCs) were calculated for each of the subscales, using 0.30 as criterion. ${ }^{30}$ If the percentage of missing values was acceptably low ( $<15 \%)$ and considered to be missing at random, we used the listwise deletion approach.

Otherwise, missing values were substituted according to the 'mean value of valid subtests principle'.

\section{Clients' preferences}

Importance scores on the components and the individual items of the QUOTE ${ }^{\text {prenatal }}$ were calculated as the proportion of clients who rated these components and individual items as important or very important. ${ }^{19,31}$ We considered previsit scores of 3 or 4 on individual-itemlevel to indicate importance or high importance.

Because of the fact that we used mean values of scores on individual items to compute the scores on the components, we used 2.50 rather than 3 as a threshold to indicate importance or high importance. The components or individual items of the QUOTE $^{\text {prenatal }}$ were classified as important for all clients if components and/or items were identified as important or very important by more than $75 \%$ of the participants. ${ }^{19}$ Clients' experiences: perceived performances Postvisit measures of experiences were only calculated for clients who had considered certain items as important or very important previsit. Postvisit scores of 3 or 4 on individual items were considered as indicating that preferences were met well or very well. Postvisit scores higher than 2.50 on the components were considered as indicating that preferences were well or very well met, an approach similar to that used in earlier studies. ${ }^{24}$ The criterion for well-met preferences was defined as having at least $75 \%$ of the respondents reporting a performance score of 3 or 4 on item level and higher than 2.50 on components. ${ }^{19}$ Analyses of subgroups Importance scores and perceived performance scores on each component were subsequently rated for the following groups separately: women versus partners, nulliparae versusmultiparae (women and partners) and women younger than and at or older than 36 years. Groups were compared to examine differences between these groups using regression analysis (method ENTER). Analyses were carried out using SPSS 17.0.2. 
Martin, L., Dulmen, S. van, Spelten, E., Jonge, A. de, Cock, P. de, Hutton, E. Prenatal counseling/ for congenital anomaly tests: parental preferences and perceptions of midwife performance.

Prenatal Diagnosis: 2013, 33(4), 341-353

\section{Ethical considerations}

The design of the study was approved by the Institutional Review Board of the VU University Medical Centre and the Medical Ethical Committee of the VU Medical Centre, Amsterdam, the Netherlands. Local declarations of intent were provided by all participating midwives.

\section{RESULTS}

\section{Participants}

Of the 680 eligible pregnant women, 538/680 (79\%) and 403/ 538 (75\%) of their partners agreed to participate. Previsit data were available for all respondents; the percentage of missing values for items ranged from $0.7 \%$ to $2.4 \%$ and was considered to be random. The mean age of the pregnant women was 29.4 years (SD $=4.2)$ and of the partners 31.8 years $(\mathrm{SD}=4.9)$.

Fifty percent of clients had completed education up to high school level, and 49\% had completed higher vocational or university education. Of the pregnant women, 228 were nulliparae (42\%) and 309 were multiparae (57\%). For 209 (51\%) of the partners, it was the first time their partner was pregnant, whereas 187 (46\%) had prior experience. Nine hundred thirty four (99\%) participants completed the Dutch questionnaire and seven (0.7\%) the English questionnaire (Table 1$)$.

A comparison between women who agreed and women who declined to participate in the study showed no significant difference with regard to age (mean 29.4 vs 30.1 years, $\mathrm{p}=0.11$ ), whereas rates of multiparity (77\% vs 58\%, $\mathrm{p}<0.001)$ and non-Dutch participants $(25 \%$ vs $15 \%, \mathrm{p}<0.001)$ were higher in the nonresponse group than in the response group.

\section{Quality of care through clients' eyes prenatal questionnaire}

The PCAs were conducted for the importance scores on the set of 56 items. The Kaiser-Meyer-Olkinmeasure (0.95) and Barlett test $\left(X^{2}=21\right.$ 607.8; $\left.p=0.000\right)$ demonstrated the legitimacy of the PCA.

A three-component solution that explained $43 \%$ of the variance was chosen (Table 2). The three distinguishable components appeared to represent client-midwife relation, health education and decision-making support. The 15-item component client- midwife relation reflects affective communication such as showing empathy, putting clients at ease, taking time and being professional; the 24-item component health education covers medical test information, (test) procedural information, risk information and societal information (e.g.costs of prenatal tests and eligibility for tests); and the 16- item component decision-making support includes items enquiring about values, social support and pressure on decision making and discussion about the different options and outcomes of scenarios (Tables 2 and 3).

One item, namely 'it is important that the midwife mentions the costs of prenatal testing' (Q34), loaded highest on decisionmaking support but loaded also $>0.32$ on health education. It was therefore placed in the health education component because we considered it to be a health education topic rather than a decision-making support topic. Table 3 shows the Cronbach's a found for each of the three components of the

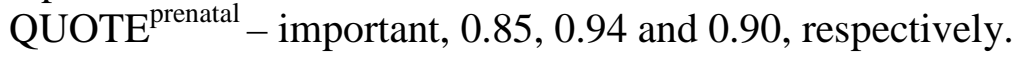

Most corrected ITCs were higher than the threshold of 0.30 (ranging up to 0.73), except for Q2 (ITC = 0.27), which we excluded from further analyses. 
Martin, L., Dulmen, S. van, Spelten, E., Jonge, A. de, Cock, P. de, Hutton, E. Prenatal counseling for congenital anomaly tests: parental preferences and perceptions of midwife performance. Prenatal Diagnosis: 2013, 33(4), 341-353

After PCA, we considered the 15 remaining items of the client-midwife relation component to be generic for counseling and the 40 items of the components health education and decision-making support to be specific to the prenatal counseling setting.

\section{Clients' preferences}

Table 3 shows that two components of the QUOTE ${ }^{\text {prenatal }}$ can be considered as important for all clients: client-midwife relation (97\%) and health education (86\%). One third of the clients (34\%) considered the component decision-making support as either important or very important.

Looking at item level, we can see in Table 4 the percentages of clients who rated the individual items of the three components as important or very important, ranging from high to low. Scores on individual client-midwife relation items ranged from $60 \%$ to $100 \%$. Of these 15 items, 13 can be considered as important for all clients because these items were listed as important or very important by more than $75 \%$ of the respondents, with highest scores for the item 'Listens to what I am trying to ask' (Q6). Scores on health education items ranged from $54 \%$ to $95 \%$. Of the 24 items, 17 were listed as important or very important by more than $75 \%$ of the participants and thus can be considered as important to all clients, with highest scores for the item 'Discusses the possible negative implications of prenatal screening for the unborn child' (Q29). None of the scores on decision-making support reached the threshold of $75 \%$. The highest score (70\%) was found for the item 'Advises me about whether or not to take the prenatal tests' (Q9).

\section{[TABLE 1]}

\section{Postvisit perceived performances}

Table 2 shows that most clients who rate client-midwife relationship, health education and decision-making support previsit as important or very important report positive experiences postvisit regarding the first two components, but these clients report less positive experience regarding decision-making support.

At an item level, Table 4 shows that more than $25 \%$ of the clients who attached high importance (score 3 or 4 ) to items of health education experienced a lack of performance (score 1 or 2 ) on 13 items of this 24-item component. A gap between preferences and perceived performances on the item perceived as most important, 'Discusses the possible negative implications of prenatal screening for the unborn child' (Q29), was perceived by $25 \%$ of the clients.

Moreover, Table 4 shows that more than $25 \%$ of the clients rated perceived performance of their midwives as 1 or 2 on 12 items of the 16-item decision-making support component.

A gap between preferences and perceived performances on the item perceived as most important of this component, 'Advises me about whether or not to take the prenatal tests' (Q9), was perceived by 37\%.

\section{Subgroups}

Regression analyses on previsit outcome variables showed that, previsit, partners rate the client-midwife relation as significantly less important than did pregnant women ( $\mathrm{b}=-1.745 ; \mathrm{p}=0.000)$ and that multiparae rate both health education and decision making support as less important than did nulliparae $(b=-0.924, p=0.000$, and $\mathrm{b}=-0.476, \mathrm{p}=0.001$, respectively; Table 5). 
Martin, L., Dulmen, S. van, Spelten, E., Jonge, A. de, Cock, P. de, Hutton, E. Prenatal counseling for congenital anomaly tests: parental preferences and perceptions of midwife performance.

Prenatal Diagnosis: 2013, 33(4), 341-353

Regression analyses on postvisit outcome variables showed that compared with nulliparae, multiparae perceived the performance of their midwives in terms of health education to be lower ( $b=-1.125, p=0.000$; Table 6).

\section{Organization}

Table 4 shows that $76 \%$ of the clients wanted to be invited to the counseling consultation together with their partner; less than half of them actually perceived they were.

\section{[TABLE 2]}

\section{DISCUSSION}

The current study presents a new research questionnaire to assess parental preferences regarding prenatal counseling for congenital anomaly tests and parental perceptions of midwives' performance. The QUOTE ${ }^{\text {prenatal }}$ consists of three components, which show sufficient reliability: client-midwife relation, health education and decision-making support. In addition, the QUOTE ${ }^{\text {prenatal }}$ was used to evaluate current parental preferences concerning prenatal counseling. Results indicate that all clients perceive the client-midwife relation as either important or very important, most clients see health education as important or very important and one third of the clients value decision-making support as either important or very important. Furthermore, the present study found that clients perceive that midwives largely act according to their previsit preferences to build a client-midwife relationship and receive health education but that they fail to fully oblige clients' preferences regarding decision-making support.

Genetic counseling should ideally consist of health education and decision-making support. ${ }^{9,12,32}$ In line with this theoretical model of counseling, our findings showed that most clients have indeed strong preferences for health education. However, only one third of our population expressed strong preferences for decision-making support, nulliparae more so than multiparae. An explanation for the contradiction of the counselling model and the preferences of clients prior to counseling might be that clients are more familiar with the midwife's role as a health educator than as a counselor who gives decision-making support.

The decision to accept or decline prenatal screening is in some respects a moral decision, and therefore, clients cannot expect professionals to make these decisions for them.

However, they can expect support in making these decisions as empowerment to make their own decision, which is part of the nondirective attitude approach during counseling that has been the norm. ${ }^{32-35}$ This study suggests that empowerment in making a decision may not be enough; more than two third of the participants prefer getting advice on whether or not to test. This may be a call for a more directive approach of counseling.

Our findings reflect the perception of clients whether they got their preferred advice or not. Thus, although our questionnaire was not developed to measure directiveness, the preference of clients that midwives provide advice seems to be in line with more recent research into decision-making support in counseling that stresses the need to use the shared decision-making model during counseling. ${ }^{35-37}$ Health professionals using this model can tailor the extent of decision-making support to their clients' 
Martin, L., Dulmen, S. van, Spelten, E., Jonge, A. de, Cock, P. de, Hutton, E. Prenatal counseling for congenital anomaly tests: parental preferences and perceptions of midwife performance.

Prenatal Diagnosis: 2013, 33(4), 341-353

individual preferences. However, Dutch society decided that ultimately the choice for prenatal screening should be well informed but made by couples themselves. The QUOTE ${ }^{\text {prenatal }}$ appeared to be able to detect issues that need improvement to ensure that prenatal counseling is in line with client preferences. Despite the relative positive experience of clients with the offered health education, midwives in our population only appear to inform clients adequately on about two thirds of the necessary health education aspects; from the clients' perceptions, one third of the procedural, societal and risk-related aspects of health education was not adequately discussed during counseling.

\section{[TABLE 3, 4, 5 AND 6]}

This was more true in perceptions of multiparae compared with those of nulliparae; midwives might have anticipated prior knowledge among multiparae and therefore omitted parts of the health education. The high number of health education issues that need improvement may reflect the results of Houwink et al. ${ }^{45}$ that Dutch midwives, at least in the perception of clinical genetic professionals, have a lack of genetic knowledge.

Our study indicated that improvement is warranted in decision-making support as well, for those clients who did rate decision-making support as important, which occurred more frequently among nulliparae than multiparae. Prior to initiating, counseling midwives or other prenatal genetic counselors might be advised to consider first whether a client wants support with decision making. The QUOTE $^{\text {prenatal }}$ and the shared decision-making model can be used to assess preferences regarding prenatal counseling.

To our knowledge, this is the largest nationally representative study of pregnant women's and their partners' previsit preferences and postvisit experiences regarding prenatal counseling for congenital anomaly tests. The proportion of participating clients compared with those eligible was relatively high (79\%). Because our sample was heterogeneous in terms of age, parity and religious background, it appears that the findings can be generalized to the wider population of clients of primary midwifery practices, keeping in mind the relatively small proportion of lowereducated participants and participants of non-Dutch origin. The mean age of our pregnant population was similar to the mean age of Dutch pregnant women (29.4 vs 31 years), and the proportions of nulliparae and multiparae (41\% and 57\%, respectively) differed slightly from the Dutch population (45\% and 55\%, respectively). ${ }^{38}$ The proportion of non-Dutch participants in our study was $15 \%$ versus $20 \%$ pregnant residents of non-Dutch origin in the whole country. ${ }^{38}$ However, no differentiation between Western origin and non-Western origin of non-Dutch participants was made.

Additional research would be useful to assess whether the previsit preferences found in this study also represent the preferences of clients from non-Dutch, non-Western origin.

\section{CONCLUSION}

The results of this study indicate that Dutch midwives

- largely act according to clients' preferences with respect to building a clientmidwife relationship and receiving health education, 
Martin, L., Dulmen, S. van, Spelten, E., Jonge, A. de, Cock, P. de, Hutton, E. Prenatal counseling for congenital anomaly tests: parental preferences and perceptions of midwife performance.

Prenatal Diagnosis: 2013, 33(4), 341-353

- may have to improve some aspects of their health education by discussing procedural, societal and risk aspects to facilitate an informed choice,

- adjust their counseling for the smaller group of clients who rate decisionmaking

support as important,

- should invite clients together with their partner for prenatal counseling and

- can use the QUOTEprenatal to assess their clients preferences previsit to tailor their

counseling to these preferences.

\section{ACKNOWLEDGEMENTS}

We owe our special thanks to the participating pregnant women and their partners and to the midwives and assistants of the participating midwifery practices, who made this study possible.

\section{[BOX 1 AND 2]}

\section{REFERENCES}

1. Jakobsen TR, Sogaard K, Tabor A. Implications of a first trimester Down's syndrome screening program on timing of malformation detection. Acta Obstetrica et Gynecologica Scandinavica. Nord Fed Society Obstet Gyn 2011;90:728-36.

2. Korenromp M. Prenatal adaptation to termination of pregnancy for fetal anomalies. Utrecht: Dissertation UMC Utrecht, 2006:11-3.

3. Tischler R, Hudgins L, Blumenfeld $\mathrm{YJ}$, et al. Noninvasive prenatal diagnosis: pregnant women's interest and expected uptake. Prenat Diagn 2011;31(13):1292-9.

4. Flessel MC, Lorey FW. The California Prenatal Screening Program: "options and choices" not "coercion and eugenics". Genetic Medicine 2011;13(8):711-3.

5. Garcia ME, Timmermans DRM, Van Leeuwen E. Rethinking autonomy in the context of prenatal screening decision-making. Prenat Diagn 2008;28:115-20.

6. Health Counsel of the Netherlands. Population screening Act: first start with a nationwide program for prenatal screening: Down's syndrome and neural tube defects. The Hague: Health Counsel of the Netherlands, 2006 publication no. 2006-03.

7. Resta RG. Defining and redefining the scope and goals of genetic counseling. Am J Med Genetics Part C 2006;142C:269-75.

8. Liefhebber S, VanDamC,Waelput A. Dutch professional profilemidwives.

Utrecht: Royal Dutch organization of Midwives (KNOV), 2005.

9. Meiser B, Irle J, Lobb E, et al. Assessment of the content and process of genetic counseling: a critical review of empirical. Studies. J Genetic Couns 2008;17:434-51.

10. Resta R, Bowles - Biesecker B, Bennett RL, et al. A new definition of genetic counseling: National Society of Genetic Counselors' Task Force report. J Genet Counsel 2006;15(2):77-83.

11. Van Zwieten MCB. The importance of an informed choice, but what concerns the choice? The complex decision-making in prenatal screening. De Psycholoog 2008;43:205.

12. Roter $D$, Ellington $L$, Hamby Erby L, et al. The genetic counseling video project (GCVP). Am J Med Genetics Part C 2006; (142C): 209-20.

13. De Boer J, Zeeman K. KNOV-guideline prenatal midwifery led care: recommendation for coaching, interaction and information giving.

Utrecht: KNOV, 2008:17-46.

14. Durand MA, Stiel M, Boivin J, et al. Information and decision support needs of parents considering amniocentesis: interviews with pregnant women and health professionals. Health Expect 2010;13(2):125-38.

15. Kreuter MW, Strecker VJ, Glassman B. One size does not fit all: the case for tailoring print materials. Annals Behav Medicine 1999;21(4):276-83.

16. Mearns D, Thorne B. Person-Centered Counselling in Action. London: Sage Publications, (2nd edn), 1999;5-21. 
Martin, L., Dulmen, S. van, Spelten, E., Jonge, A. de, Cock, P. de, Hutton, E. Prenatal counseling/ for congenital anomaly tests: parental preferences and perceptions of midwife performance.

Prenatal Diagnosis: 2013, 33(4), 341-353

17. Petty R, Cacioppo J. The elaboration likelihood model of persuasion.

Advances Experimental Social Psychology 1986;19:123-205.

18. Todd J, Bohart AC. Foundations of Clinical and Counseling Psychology.

New York: HarperCollins College Publishers, (3rd edn), 2005;209-39.

19. Van Weert JCM, Jansen J, Bruijn de GJ, et al. QUOTE chemo : a patientcentered instrument to measure quality of care preceding chemotherapy treatment through the patient's eyes. Europ J Cancer 2009;45(17):2967-76.

20. Shiloh S, Gerad L, Goldman B. Patients' information needs and decision-making processes: what can be learned from genetic counselees? Health Psychol 2006;25(2):2119.

21. Kessler S Psychological aspects of genetic counseling: XI. Teaching and counseling. J Genetic Counsel 1999a;6:287-95.

22. RIVM. [WWW document]. URL http://www.rivm.nl/Onderwerpen/ Onderwerpen/D/Downscreening.html [accessed on 19 July 2012].

23. Mannien J, Klomp T, Wiegers T, et al. Evaluation of primary care midwifery in the Netherlands: design and rationale of a dynamic cohort study (DELIVER). BMC Health Serv Res 2012;12(69), DOI: 10.1186/1472- 6963-12-69.

24. Pieterse A, Van Dulmen S, Ausems M, et al. QUOTE-GENEca: development of a counselee-centered instrument to measure needs and preferences in genetic counselling for hereditary cancer.

Psychooncology 2005;14:361-75.

25. Sixma HJ, Van Campen C, Kerssens JJ, et al. Quality of care from the patients' perspectives: from theoretical concept to a new measuring instrument. Health Expect 1998;1:82-95.

26. Van den Brink-Muinen A, Van Dulmen AM, Jung HP, et al. Do our talks with patient meet their expectations? Yes, for the most part. J Fam Pract 2007;56:559-68.

27. Nijkamp MD, Sixma HJ, Afman H, et al.. Quality of care from the perspective of the cataract patient: the reliability and validity of the QUOTE-cataract. British J Ophthalmol 2002;86:840-2.

28. Costello $A B$, Osborne JW. Exploratory factor analysis: four recommendations for getting the most from your analysis. Pract Assess Res Eval 2005;10(7):1-9.

29. Cook DA, Beckman TJ. Current concepts in validity and reliability for psychometric instruments: theory and application. Am J Med 2006;119:166.e7-16.

30. Field A. Discovering Statistics Using SPSS. London: Sage Publishers, (3rd edn), 2009;627-85.

31. Gutteling JJ, De Man RA, Busschbach JJ, et al. Quality of health care and patient satisfaction in liver disease: the development and preliminary results of the QUOTE-Liver questionnaire. BMC Gastroenterol 2008;8:25-32.

32. Ellington L, Roter DL, Dudley W, et al. Communication analysis of BRCA1 genetic counseling. J Genet Couns 2005;14:377-86.

33. Beckendorf JL, Prince MB, Rose MA, et al. Does indirect speech promote non-directive genetic counseling? Results of a sociolinguistic investigation. Am J Med Genetics 2001;106:199-207.

34. Van den Berg M, Timmermans DR, Ten Kate LP, et al. Are counsellors' attitude influencing pregnant women's attitudes and decisions on prenatal screening? Prenat Diagn 2007;27:518-24.

35. Smets $\mathrm{E}$, Van Zwieten M, Michie S. Comparing genetic counseling with non-genetic health care interactions: two of a kind? Patient Educ Couns 2007;68:225-34.

36. Van Zwieten MCB. Non-directivity: a controversial concept. TVG 2003;13(1):20-2.

37. Van Zwieten MCB, Willems D, Knegt L, et al. Communication with patients during the prenatal testing procedure : an explorative qualitative study. Pat Educ and Couns 2006;63:161-8.

38. The Netherlands Perinatal Registry. 10 Years Perinatal Registration in the Netherlands; an Overview. Utrecht: Stichting Perinatale Registratie Nederland, 2011;26-39.

39. Van den Berg M, Timmermans DR, Ten Kate LP, et al. Informed decision making in the context of prenatal screening. Patient Educ Couns 2006;63(1-2):110-7.

40. Kleinveld JH. Psychological Consequences of Prenatal Screening.

Amsterdam: Dissertation VU Medical Centre, 2008;18. 
Martin, L., Dulmen, S. van, Spelten, E., Jonge, A. de, Cock, P. de, Hutton, E. Prenatal counseling for congenital anomaly tests: parental preferences and perceptions of midwife performance. Prenatal Diagnosis: 2013, 33(4), 341-353

41. de Grient- Dreux A, Kooijman H, Korenromp M. Prenatal tests. About Choices and Dilemmas. Houten: Het Spectrum 2008:46-62.

42. National Public Health Compass. [WWW document]. URL http://www. nationaalkompas.nl/gezondheid-en-ziekte/ziekte-en-aandoeningen/ aangeboren-

afwijkingen/centrale-zenuwstelsel/diagnose-behandeling.html [accessed on 19 July 2012].

43. Wiegers TA, Hingstman L. Het veranderende takenpakket van verloskundigen. Nieuwe cijfers over tijdsbesteding aan specifieke taken. TvV 2008;3:19-24.

44. Hoogendoorn M, Hamberg-van Reenen HH, van Genugten MLL, et al. Comparison of costs and effects of prenatal screening methods for Down's syndrome and neural tube defects. Bilthoven: RIVM rapport, 2004; publication no. 230041001/2004: 7-12.

45. Houwink EJF, van Luijk SJ, Henneman L, et al. Genetic educational needs and role of genetics in primary care: a focus group study with multiple perspectives. BMC Fam Pract 2011;12:5.

\section{[APPENDIX 1 AND APPENDIX 2]}

\section{TABLES AND APPENDIXS}

\begin{tabular}{|c|c|c|}
\hline Characteristics of the sample & $\begin{array}{l}\text { Test sample women results } \\
\text { Mean (SD), N (\%) missing }\end{array}$ & $\begin{array}{c}\text { Test sample partners results, } N(\%) \\
\text { Mean (SD), } N(\%) \text { missing }\end{array}$ \\
\hline Age & 29.4 years (4.2), $N=7(1.3)$ & 31.8 years $(4.9), N=7(1.7)$ \\
\hline Age at first pregnancy & 27.9 years $(4.0), N=0$ & 30.4 years $(4.5), N=0$ \\
\hline Weeks pregnant & 8.6 weeks $(2.1), N=39(7.2)$ & 8.6 weeks (SD), $N=39(7.2)$ \\
\hline Parity & $\begin{array}{c}\text { Nulliparae: } N=219(40.7) \\
\text { Multiparae: } N=307(57.0) \\
\text { Missing: } N=12(2.3)\end{array}$ & $\begin{array}{c}\text { Nullipartner: } N=205(50.8) \\
\text { Multipartner: } N=185(45.9) \\
\text { Missing: } N=13(3.2)\end{array}$ \\
\hline Education & $\begin{array}{l}\text { Low: } N=7(1.3) \\
\text { Middle: } N=250(46.5) \\
\text { High: } N=278(51.7) \\
\text { Missing: } N=3(0.6)\end{array}$ & $\begin{array}{l}\text { Low: } N=6(1.4) \\
\text { Middle: } N=208(51.6) \\
\text { High: } N=186(46.2) \\
\text { Missing: } N=3(0.7)\end{array}$ \\
\hline Ethnic origin ${ }^{a}$ & $\begin{array}{c}\text { Dutch: } N=454(84.4) \\
\text { Non-Dutch: } N=79(14.7) \\
\text { Missing: } N=3(0.6)\end{array}$ & $\begin{array}{c}\text { Dutch: } N=346(85.9 \%) \\
\text { Non-Dutch: } N=49(12.2) \\
\text { Missing: } N=8(2)\end{array}$ \\
\hline Marital status & $\begin{array}{l}\text { Partner: } N=515(95.7) \\
\text { Single: } N=20(3.7) \\
\text { Missing: } N=3(0.6)\end{array}$ & $\begin{array}{c}\text { Partner: } N=387(96.0) \\
\text { Divorced/single: } N=12(3.0) \\
\quad \text { Missing: } N=4(1.0)\end{array}$ \\
\hline Religion & $\begin{array}{c}\text { Believers: } N=262(48.7) \\
\text { Non-believers: } N=267(49.6) \\
\text { Missing: } N=9(1.7)\end{array}$ & $\begin{array}{c}\text { Believers: } N=187(46.4) \\
\text { Non-believers: } N=207(51.4) \\
\text { Missing: } N=9(2.2)\end{array}$ \\
\hline Gender & & $\begin{array}{c}\text { Male: } N=396(98.2) \\
\text { Female: } N=6(1.4) \\
\text { Missing: } N=1(0.4)\end{array}$ \\
\hline
\end{tabular}

In the Netherlands, ethnic origin is defined by country of birth of a person's parents. If one or both of the parents of a person are bom outside the Netherlands, this person is considered non-Dutch (Dutch National Office of Statistics; Statistics Netherlands). 
Martin, L., Dulmen, S. van, Spelten, E., Jonge, A. de, Cock, P. de, Hutton, E. Prenatal counseling for congenital anomaly tests: parental preferences and perceptions of midwife performance.

Prenatal Diagnosis: 2013, 33(4), 341-353

Table 2 Varimax rotated component matrix with three-factor solution on the 56 QUOTE variance, and variance explained by each component $(N=941)$

\begin{tabular}{|c|c|c|c|}
\hline \multirow[b]{2}{*}{ ltems } & \multicolumn{3}{|c|}{ Component } \\
\hline & 1 & 2 & 3 \\
\hline \multicolumn{4}{|l|}{ Health education } \\
\hline Q26 explains which anomalies can be identified using prenatal tests & 0.760 & & \\
\hline Q31 explains usefulness of prenatal screening (what can a client do with it after obtaining results) & 0.756 & & \\
\hline Q32 tells me about all different types of prenatal tests available & 0.752 & & \\
\hline Q41 explains why the client is or is not eligible for certain prenatal tests & 0.720 & & \\
\hline Q43 explains which prenatal tests will be performed first and which will be performed later, if required and/or necessary & 0.717 & & \\
\hline Q48 discusses all my options with regard to prenatal screening and the implications & 0.705 & & \\
\hline Q42 explains what will happen during prenatal tests & 0.691 & & \\
\hline Q39 tells me about my chances of having a child with a congenital abnomality during the pregnancy & 0.689 & & \\
\hline Q27 explains which anomalies can NOT be idenified using prenatal tests & 0.688 & & \\
\hline Q45 explains how long I may take to decide whether or not to have the prenatal tests & 0.657 & & \\
\hline Q29 discusses possible negative implications of prenatal screening for the unbom child & 0.642 & & \\
\hline Q46 explains how long I may take to decide whether or not to terminate the pregnancy, should the test results show an abnormality & 0.635 & & \\
\hline Q38 explains how the changes of a birth defect are calculated for our unborn child & 0.604 & 0.334 & \\
\hline Q28 provides medical information about the anomalies that are being tested for & 0.597 & & \\
\hline Q40 talks to me about how my risk of having a child with a birth defect will affect me & 0.584 & 0.423 & \\
\hline Q44 explains who will give me the results of the prenatal tests and how (verbally, in writing or by telephone) & 0.554 & 0.354 & \\
\hline Q37 explains how often congenital anomalies occur in pregnant women of my age & 0.546 & 0.353 & \\
\hline Q35 tells me about the incidence of birth defects in the Netherlands & 0.524 & 0.396 & \\
\hline Q36 asks about my family's history of birth defects & 0.513 & & \\
\hline Q13 provides information on prenatal tests & 0.510 & & \\
\hline Q33 tells me how prenatal screening can affect my emotions and mental well being & 0.437 & 0.397 & \\
\hline Q58 makes sure that the topics I consider to be important are discussed at length & 0.413 & & \\
\hline Q56 only discusses specific information about follow-up tests and possible defects with me if it becomes clear that I will need them & 0.401 & & \\
\hline \multicolumn{4}{|l|}{ (Moral) decision-making support } \\
\hline Q51 asks whether my family, friends, or other people close to me would support my decision about prenatal screening & & 0.751 & \\
\hline $\begin{array}{l}\text { Q54 asks whether my family, friends, or other people close to me would support my decision to terminate the pregnancy if the } \\
\text { child were to have a congenital abnormality }\end{array}$ & & 0.745 & \\
\hline Q53 asks whether test results indicating that my unborn child has a birth defect would cause problems with my conscience & 0.304 & 0.696 & \\
\hline Q52 asks me what I think constitutes a healthy child & & 0.693 & \\
\hline Q55 asks how I think I will react to the results of the prenatal tests & & 0.688 & \\
\hline Q50 asks me to explain my decision to take/not to take the prenatal tests & & 0.665 & \\
\hline Q49 talks to me about how my family and I would react to a child with a birth defect & 0.360 & 0.644 & \\
\hline Q25 encourages me and my partner to talk together about prenatal screening & & 0.597 & \\
\hline Q14 enquires about my standards, values, and views on prenatal tests & & 0.540 & 0.300 \\
\hline Q21 is interested in who l am & & 0.534 & 0.423 \\
\hline Q30 tells me what the Dutch government aims to achieve by providing prenatal tests & 0.313 & 0.515 & \\
\hline Q20 asks me questions that make me think & & 0.413 & \\
\hline Q22 responds to what I already know about prenatal screening & & 0.402 & \\
\hline Q34 tells me how much prenatal tests cost & 0.324 & 0.396 & \\
\hline Q11 is understanding about my ideological background or my religion & & 0.394 & 0.327 \\
\hline Q3 tells me which Internet sites I can use to find information about prenatal testing & & 0.375 & \\
\hline Q9 advises me about whether or not to take the prenatal tests & 0.327 & 0.352 & \\
\hline
\end{tabular}


Martin, L., Dulmen, S. van, Spelten, E., Jonge, A. de, Cock, P. de, Hutton, E. Prenatal counseling for congenital anomaly tests: parental preferences and perceptions of midwife performance.

Prenatal Diagnosis: 2013, 33(4), 341-353

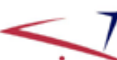

Table 2 (Continued)

\begin{tabular}{|c|c|c|c|}
\hline \multirow[b]{2}{*}{ ltems } & \multicolumn{3}{|c|}{ Component } \\
\hline & 1 & 2 & 3 \\
\hline \multicolumn{4}{|l|}{ Client-midwife relationship } \\
\hline Q6 listens to what I am trying to ask & & & 0.702 \\
\hline Q8 gives me enough time to explain myself properly & & & 0.683 \\
\hline Q5 takes my concerns seriously & & & 0.683 \\
\hline Q15 makes clear that I can ask anything I want to know & & & 0.604 \\
\hline Q4 puts me at ease & & & 0.563 \\
\hline Q1 takes plenty of time to answer my questions & & & 0.563 \\
\hline Q16 uses clear and comprehensible language & & & 0.520 \\
\hline Q12 knows what I am talking about & & & 0.517 \\
\hline Q7 is open and honest about every aspect of my pregnancy & & & 0.505 \\
\hline Q10 shows empathy & & 0.430 & 0.489 \\
\hline Q18 tells me that I can always contact her/him with any question I may have (induding when the practice is closed) & & 0.318 & 0.486 \\
\hline Q24 gives me the feeling that she is tuning in to me as a person & & 0.347 & 0.482 \\
\hline Q2 is professional & & & 0.389 \\
\hline Q19 accepts my decision on whether or not to agree to prenatal testing & & & 0.365 \\
\hline Q17 gives me (additional) wilten information & & 0.301 & 0.351 \\
\hline Q23 paints a realistic picture (not just through 'rose-tinted spectades') & & & 0.333 \\
\hline
\end{tabular}


Martin, L., Dulmen, S. van, Spelten, E., Jonge, A. de, Cock, P. de, Hutton, E. Prenatal counseling for congenital anomaly tests: parental preferences and perceptions of midwife performance. Prenatal Diagnosis: 2013, 33(4), 341-353

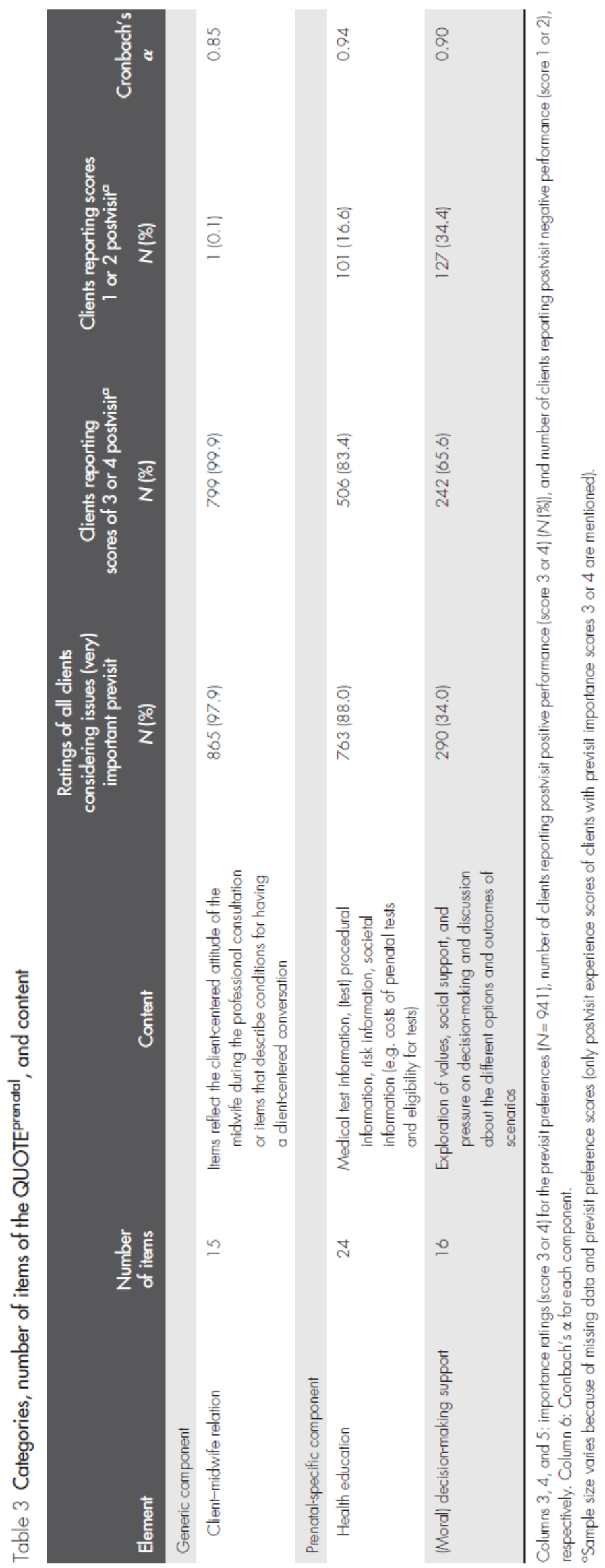


Martin, L., Dulmen, S. van, Spelten, E., Jonge, A. de, Cock, P. de, Hutton, E. Prenatal counseling for congenital anomaly tests: parental preferences and perceptions of midwife performance.

Prenatal Diagnosis: 2013, 33(4), 341-353

Table 4 Client rating items as (very) important previsit $(N=941)$, clients rating items (well) done postvisit while rating these items previsit as (very) important [N (\%)], and clients rating items not or a little done during visit although having strong preferences for these items previsit $[N(\%)]$

\begin{tabular}{|c|c|c|c|c|}
\hline Number & Item description & $\begin{array}{l}\text { Clients rating items as } \\
\text { (very) important } \\
\text { previsit (\%) }\end{array}$ & $\begin{array}{l}\text { Clients rating items } \\
\text { (well) done } \\
\text { postvisiti }{ }^{\circ}, N(\%)\end{array}$ & $\begin{array}{l}\text { Clients rating items } \\
\text { (not/a little) done } \\
\text { postvisif, N(\%) }\end{array}$ \\
\hline \multicolumn{5}{|c|}{ Generic component and items } \\
\hline \multicolumn{5}{|c|}{ Client-midwife relation } \\
\hline$Q 2^{\mathrm{c}}$ & Is professional & (99.8) & $848(99.7)$ & $3(0.3)$ \\
\hline Q6 & Listens to what I am trying to ask & (99.7) & $848(99.8)$ & $2(0.2)$ \\
\hline Q5 & Takes my concerns seriously & (98.9) & $832(99.2)$ & $7(0.8)$ \\
\hline Q1 & Takes plenty of time to answer my questions & (98.3) & $841(99.6)$ & $3(0.4)$ \\
\hline Q7 & Is open and honest about every aspect of my pregnancy & (98.3) & $768(99.4)$ & $5(0.6)$ \\
\hline Q4 & Puts me at ease & (96.8) & $827(99.2)$ & $7(0.8)$ \\
\hline Q16 & Uses clear and comprehensible language & (95.1) & $821(99.8)$ & $2(0.2)$ \\
\hline Q23 & Paints a realistic picture (not [ust through 'rosettinted spectacles') & (93.8) & $731(96.8)$ & $24(3.2)$ \\
\hline Q8 & Gives me enough time to explain myself properly & (92.9) & $748(99.6)$ & $3(0.4)$ \\
\hline Q15 & Makes clear that I can ask anything I want to know & (92.5) & $798(98.8)$ & $10(1.2)$ \\
\hline Q19 & Accepts my decision on whether or not to agree to prenatal screening & (87.9) & $705(97.5)$ & $18(2.5)$ \\
\hline Q24 & Gives me the feeling that she is tuning in to me as a person & (82.8) & 663196.11 & $27(3.9)$ \\
\hline Q12 & Knows what I am talking about & $(80.9)$ & $580(83.2)$ & $117(16.8)$ \\
\hline Q18 & $\begin{array}{l}\text { Tells me that I can always contact her or him with any questions I may } \\
\text { have (including when the practice is closed) }\end{array}$ & $(79.8)$ & $621(93.4)$ & $44(6.6)$ \\
\hline Q10 & Shows empathy & $(61.7)$ & $531(97.2)$ & $15(2.8)$ \\
\hline Q17 & Gives me (additional) written information & $(60.0)$ & $422(97.2)$ & $12(2.8)$ \\
\hline \multicolumn{5}{|c|}{ Prenatal-specific components and items } \\
\hline \multicolumn{5}{|c|}{ Health education } \\
\hline Q29 & $\begin{array}{l}\text { Discusses possible negative implications of prenatal screening for the } \\
\text { unborn child }\end{array}$ & (95.2) & $467(65.5)$ & $181(24.5)$ \\
\hline Q26 & Explains which anomalies can be identified using prenatal screeening & (90.7) & $655(89.0)$ & $81(11.0)$ \\
\hline Q31 & $\begin{array}{l}\text { Explains the usefulness of prenatal screening (what I can decide to do } \\
\text { eventually) }\end{array}$ & $(90.0)$ & $651(89.3)$ & $78(10.7)$ \\
\hline Q58 & $\begin{array}{l}\text { Makes sure that the topics I consider to be important are discussed at } \\
\text { length }\end{array}$ & (88.8) & $665(92.4)$ & $54(7.6)$ \\
\hline Q13 & Provides information on prenatal screening & (88.2) & $314(59.1)$ & $217(40.9)$ \\
\hline Q42 & Explains what will happen during the prenatal tests & $(87.0)$ & $485(69.4)$ & $214(30.6)$ \\
\hline Q32 & Tells me about all the different types of prenatal tests & (86.8) & $650(91.3)$ & $62(8.7)$ \\
\hline Q27 & Explains which anomalies cannot be identified using prenatal tests & $(85.4)$ & $449(64.0)$ & $253(36.0)$ \\
\hline Q39 & $\begin{array}{l}\text { Tells me about my chances of having a child with a congenital } \\
\text { abnormality during this pregnancy }\end{array}$ & (83.6) & $360(58.4)$ & $256(41.6)$ \\
\hline Q43 & $\begin{array}{l}\text { Explains which prenatal tests will be performed first and which will be } \\
\text { performed later, if required and/or necessary }\end{array}$ & (82.7) & $583(85.6)$ & $98(14.4)$ \\
\hline Q41 & Tells me why I am or am not eligible for certain prenatal tests & $(82.4)$ & $497(68.6)$ & $211(31.4)$ \\
\hline Q48 & $\begin{array}{l}\text { Discusses all my options with regard to prenatal screening and the } \\
\text { implications }\end{array}$ & $(82.3)$ & $344(83.9)$ & $62(16.1)$ \\
\hline Q46 & $\begin{array}{l}\text { Explains how long I may take to decide whether or not to terminate the } \\
\text { pregnancy, should the test results show an abnormality }\end{array}$ & (81.8) & $380(58.8)$ & $289(43.2)$ \\
\hline Q45 & $\begin{array}{l}\text { Explains how long I may take to decide whether or not to have the } \\
\text { prenatal tests }\end{array}$ & $(81.0)$ & $518(77.9)$ & $147(22.1)$ \\
\hline Q40 & $\begin{array}{l}\text { Talks to me about how } m y \text { risk of having a child with a birth defect will } \\
\text { affect me }\end{array}$ & (76.3) & $236(62.3)$ & $143(37.7)$ \\
\hline
\end{tabular}


Martin, L., Dulmen, S. van, Spelten, E., Jonge, A. de, Cock, P. de, Hutton, E. Prenatal counseling for congenital anomaly tests: parental preferences and perceptions of midwife performance.

Prenatal Diagnosis: 2013, 33(4), 341-353

Table 4 (Continued)

\begin{tabular}{|c|c|c|c|c|}
\hline Number & Item description & $\begin{array}{l}\text { Clients rating items as } \\
\text { (very) important } \\
\text { previsif (\%) }\end{array}$ & $\begin{array}{l}\text { Clients rating items } \\
\text { (well) done } \\
\text { postvisit }{ }^{a}, N(\%)\end{array}$ & $\begin{array}{c}\text { Clients rating items } \\
\text { (not/a little) done } \\
\text { postvisif, } N(\%)\end{array}$ \\
\hline Q28 & Provides medical information about the anomalies that are being tested for & $(76.0)$ & $486(77.3)$ & $143(22.7)$ \\
\hline Q36 & Asks about my family's history of birth defects & (77.1) & $544(94.1)$ & $34(5.9)$ \\
\hline Q56 & $\begin{array}{l}\text { Only discusses specific information about follow-up tests and possible } \\
\text { defects with me if it becomes clear that I will need them }\end{array}$ & $(75.1)$ & $351(59.7)$ & $237(40.3)$ \\
\hline Q33 & $\begin{array}{l}\text { Tells me how prenatal screening can affect my emotions and mental } \\
\text { wellbeing }\end{array}$ & (74.9) & $255(68.7)$ & $116(31.3)$ \\
\hline Q38 & $\begin{array}{l}\text { Explains how the chances of a bith defect are calculated for our unborn } \\
\text { child }\end{array}$ & $(72.5)$ & $442(76.7)$ & $134(23.3)$ \\
\hline Q44 & $\begin{array}{l}\text { Explains who will give me the results of the prenatal tests and how } \\
\text { (verbally, in writing, or by telephone) }\end{array}$ & $(68.3)$ & $326(56.3)$ & $253(43.7)$ \\
\hline Q37 & $\begin{array}{l}\text { Explains how often congenital anomalies occur in pregnant women of } \\
\text { my age }\end{array}$ & $(68.4)$ & $396(69.6)$ & $173(30.4)$ \\
\hline Q34 & Tells me how much prenatal tests cost & $(55.9)$ & $285(61.0)$ & $182(39.0)$ \\
\hline Q35 & Tells me about the incidence of birth defects in the Netherlands & (54.4) & $274(59.6)$ & $186(40.4)$ \\
\hline \multicolumn{5}{|c|}{ (Moral) decision-making support } \\
\hline Q9 & Advises me about whether or not to take the prenatal tests & $(69.8)$ & $301(62.7)$ & $179(37.3)$ \\
\hline Q22 & Responds to what I already know about prenatal screening & $|65.9|$ & $533(93.2)$ & $33(6.8)$ \\
\hline Q20 & Asks me questions that make me think & $(65.0)$ & $396(61,7)$ & $164(29.3)$ \\
\hline Q49 & $\begin{array}{l}\text { Talks to me about how my family and I would react to a child with a } \\
\text { birth defect }\end{array}$ & (54.3) & $205(55.7)$ & $163(44.3)$ \\
\hline Q50 & Asks me to explain my decision to take/not to take the prenatal tests & $(51.7)$ & $488(66.1)$ & $112(33.9)$ \\
\hline Q21 & Is interested in who I am & $(50.6)$ & $428(96.0)$ & $18(4.0)$ \\
\hline Q55 & Asks how I think I will react to the results of the prenatal tests & (49.4) & $166(48.7)$ & $175(51.3)$ \\
\hline Q53 & $\begin{array}{l}\text { Asks whether test results indicating that my unborn child has a birth } \\
\text { defect would cause problems with my conscience }\end{array}$ & $(48.2)$ & $156(46.0)$ & $183(54.0)$ \\
\hline Q25 & Encourages me and my partner to talk together about prenatal screening & $(47.0)$ & $306(82.5)$ & $65(17.5)$ \\
\hline Q14 & Enquires about my standards, values, and views on prenatal tests & (45.7) & $299(74.4)$ & $130(25.6)$ \\
\hline Q52 & Asks me what I think constitutes a healthy child & $(45.1)$ & $121(38.7)$ & $192(61.3)$ \\
\hline Q30 & $\begin{array}{l}\text { Tells me what the Dutch government aims to achieve by providing } \\
\text { prenatal tests }\end{array}$ & $(42.4)$ & $186(52.2)$ & $170(47.7)$ \\
\hline Q3 & $\begin{array}{l}\text { Tells me which Internet sites I can use to find information about prenatal } \\
\text { screening }\end{array}$ & $(37.0)$ & $180(62.5)$ & $108(37.5)$ \\
\hline Q11 & Is understanding about my ideological background or my religion & $(32.3)$ & $239(87.9)$ & $33(12.1)$ \\
\hline Q54 & $\begin{array}{l}\text { Asks whether my family, friends, or other people close to me would } \\
\text { support my decision to terminate the pregnancy if the child were to } \\
\text { have a congenital abnormality }\end{array}$ & $(22.0)$ & $239(31.8)$ & $109(59.2)$ \\
\hline Q51 & $\begin{array}{l}\text { Asks whether my family, friends, or other people close to me would } \\
\text { support my decision about prenatal screening }\end{array}$ & $(16.2)$ & $64(56.4)$ & $74(53.6)$ \\
\hline \multicolumn{5}{|c|}{ Organizational items } \\
\hline Q47 & $\begin{array}{l}\text { Asks my partner and me to come to the counseling session on prenatal } \\
\text { screening together }\end{array}$ & $(75.5)$ & $295(49.2)$ & $305(50.8)$ \\
\hline Q59 & $\begin{array}{l}\text { Makes a separate appointment for me to discuss prenatal tests (rather } \\
\text { than broaching the subject during my first appointment) }\end{array}$ & $(33.4)$ & $94(31.6)$ & $203(68.4)$ \\
\hline Q57 & $\begin{array}{l}\text { Plans two appointments to discuss prenatal tests (one to provide the } \\
\text { relevant information and one to discuss the decision) }\end{array}$ & $(21.8)$ & $67(34.2)$ & $129(65.8)$ \\
\hline
\end{tabular}

Bold figures in the first column reflect items that are important to all clients according to the threshold of $75 \%$ we used in this study.

Bold figures in the third column reflect items that were perceived to be not or slightly met during prenatal counseling by the midwives in this study.

"Figures concern clients considering the issues as either important or very im portant previsit only.

Sample size varies because of missing data.

This question was omitted from further analyses, because of the very weak item-total correlation. 
Martin, L., Dulmen, S. van, Spelten, E., Jonge, A. de, Cock, P. de, Hutton, E. Prenatal counseling for congenital anomaly tests: parental preferences and perceptions of midwife performance.

Prenatal Diagnosis: 2013, 33(4), 341-353
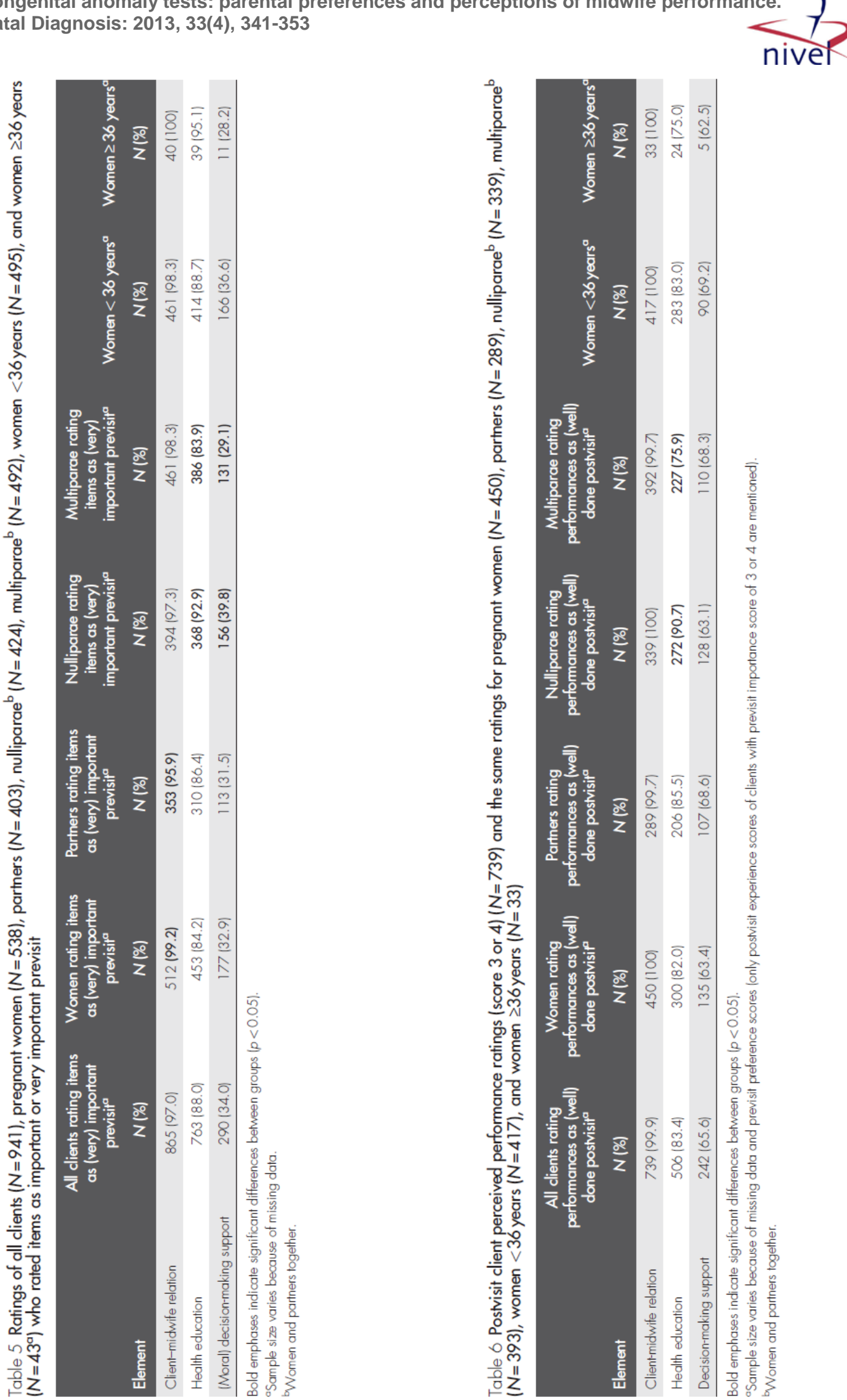


\section{WHAT'S ALREADY KNOWN ABOUT THIS TOPIC?}

- Optimizing client health decisions requires tailored communication.

- In prenatal counseling, such communication should comprise health education and decision-making support.

\section{WHAT DOES THIS STUDY ADD?}

- A valid research instrument to evaluate the preferences and experiences of parents regarding prenatal counseling.

- Clients perceive that their midwives perform well in giving health education, an aspect of care considered important by most clients

- Although fewer clients valued decision-making support, we identified a need for improvement in this aspect of care.

\section{APPENDIX 1}

\section{Prenatal testing in the Netherlands}

In the Netherlands, prenatal testing procedures are available to the public. However, Dutch law prohibits the routine introduction of prenatal tests for congenital anomalies in an attempt to protect the population against prenatal testing programs that could be a threat to the psychological and physical health of the person being screened or diagnosed. ${ }^{39}$ In other words, this law states that prenatal tests to detect severe anomalies that cannot be cured or prevented should not be offered routinely, but only after thorough informed consent. If pregnant women and their partners in the Netherlands indicate that they want information, the midwife will inform them about the following prenatal tests: Firstly, pregnant women and their partners are offered the opportunity of having the combined test (also known as first trimester screening) early in pregnancy (9-14 weeks).This test provides information on the chance of having a child with Down's syndrome (DS), trisomy 13 or 18 based on the combination of nuchal translucency measurement, first trimester maternal serum screening, and maternal age in relation to gestational age. Women older than 36 years have this screening for free, younger women have to pay (people are informed about screening). Secondly, all pregnant women and their partners are offered a standard anomaly scan (SAS) between 18 and 22 weeks gestation. The SAS is made either in hospitals or by certified midwives in primary healthcare. Only women at higher risk of carrying a fetus with chromosomal anomalies due to their family history, age 36 years or older, or elevated risk based on the combined test can have amniocentesis or chorionic villus sampling for free. ${ }^{39,40}$ Advanced ultrasound is only offered to women if anomalies are seen on the SAS or if they have an increased risk of a child with a structural abnormality which cannot be diagnosed with other prenatal diagnostic tests. ${ }^{41}$ Besides these prenatal tests, which are offered in the context of the described law, early in pregnancy (8 to 10 weeks) and in contrast with 
Martin, L., Dulmen, S. van, Spelten, E., Jonge, A. de, Cock, P. de, Hutton, E. Prenatal counseling for congenital anomaly tests: parental preferences and perceptions of midwife performance. Prenatal Diagnosis: 2013, 33(4), 341-353

prenatal tests for congenital abnormality, a routine ultrasound, used to confirm pregnancy, a possible twin pregnancy and the expected date of birth, is offered to all parents. Due to the advanced quality of the ultrasound technology, unexpected findings, such as an increased nuchal translucency, may be found as well. ${ }^{42}$

\section{APPENDIX 2}

\section{Prenatal test uptake in the Netherlands}

In the Netherlands, around 160,000 pregnant couples start their prenatal care in primary midwifery care. About 40,000 couples receive obstetrician-led prenatal care in hospitals. ${ }^{40,43}$ Seventyfive percent of the low risk couples have the SAS, about $27 \%$ of them have the combination test and about one third of all pregnant women older than 36 years have the amniocentesis or chorionic villus sampling. ${ }^{43,44}$ Due to governmental policies, the uptake of SAS has increased recently; many women experience SAS as a routine ultrasound and not as a matter in which they have a choice. ${ }^{39,42}$ As a result of medical developments and greater focus on the combination test rather than the triple test, the uptake of the combination test has increased, that of prenatal diagnostic tests has decreased. ${ }^{44}$ 